\title{
Experimental Investigation on Melting of Paraffin in Latent Thermal Energy Storage
}

\author{
Mateo Kirincic, Anica Trp, Kristian Lenic, Igor Wolf \\ Department of Thermodynamics and Energy Engineering \\ University of Rijeka, Faculty of Engineering \\ Rijeka, Croatia \\ mateo.kirincic@ @iteh.hr, anica.trp@ riteh.hr, kristian.lenic@ riteh.hr, igor.wolf@ riteh.hr
}

\begin{abstract}
This paper presents an experimental research of melting of paraffin inside a latent thermal energy storage. Experimental setup consists of a water-water heat pump, hot and cold water tanks and latent storage tank. Latent heat storage is a shell-and-tube type tank, consisting of 19 concentric tubes with eight equidistant longitudinal fins. A set of $\mathbf{3 0}$ thermocouples has been placed at various positions longitudinally and radially throughout the paraffin-side of the storage to monitor the timewise temperature changes during melting, while additional two thermocouples have been placed at water inlet and outlet positions. Data acquisition system, linked with a personal computer, was used for acquiring, processing and storing measured data. Experimental research has been performed in the Laboratory for thermal measurements at University of Rijeka, Faculty of Engineering. A set of experiments, with different water inlet temperatures, has been performed. Transient temperature changes of phasechange material (PCM) for different water inlet temperatures, and the amount of stored thermal energy have been analyzed and compared.
\end{abstract}

Keywords-latent thermal energy storage, experimental investigation, melting of paraffin

\section{INTRODUCTION}

For the past few decades, solar energy has been gaining a lot of attention due to its renewable nature and environmental benefits in comparison to conventional fossil fuels. Wider application of solar energy is somewhat hindered in the fact that it is not continuously available. Latent thermal energy storage (LTES) systems are used to store thermal energy absorbed during daytime in the form of latent heat of a phase change material (PCM), and discharge it in the nighttime, causing the PCM to release its latent heat and solidify. This allows for approximately 5-14 times more energy to be stored than in sensible thermal energy storages (STES) [1]. LTES systems are utilized in various areas, e.g. domestic heating and cooling [2], refrigeration [3], solar power plants [4] etc., and most commonly, a heat transfer fluid (HTF) is used to transfer heat into and from LTES. The selection of LTES geometry and PCM varies according to system specifications and operating conditions.

PCMs can be organic, inorganic and metallic substances. All but metallic PCMs exhibit low thermal conductivity [5], while organic ones, e.g. paraffins and fatty acids, exhibit the lowest, which hinders heat transfer rate between HTF and
PCM. In order to enhance the heat transfer rate, various methods of enhancement are used. Most commonly used enhancement is the implementation of extended surfaces or fins. Various configurations of fins, including annular, circular, longitudinal, pin and plate, have been suggested and investigated [6]. Many researchers have succeeded in installing longitudinal or rectangular fins along circumference of the PCM container [7]. Kalapala and Devanuri [8] performed an extensive review of geometric parameters and operating conditions necessary for design and optimization of LTES with fins, especially those with cylindrical configuration, i.e. double pipe, triplex tube and shell-andtube-type LTES. Al-Abidi et al. [9] report that shell-and-tube type LTES make for $70 \%$ of total LTES configurations. Agyenim et al. [10] investigated three horizontal concentric tubes storage units: one unfinned, which was the control unit, and the other two with circular and longitudinal fins. They compared the thermal performance of these configurations experimentally and concluded that the system with longitudinal fins provided the best heat transfer during melting. Gil et al. [11] performed an experimental comparison of two LTES tanks, with and without fins, during the melting process. They observed an increase in thermal effective conductivity up to $26 \%$ when using fins. Al-Abidi et al. [12] experimentally analyzed the melting and solidification processes in a triplex tube-type unit with internal and external longitudinal fins. They examined the system performance with respect to varying HTF inlet tempeature and mass flow rates. Rathod and Banerjee [13] experimentally studied melting and solidification enhancement in a shell-and-tube LTES system using longitudinal fins. A $12.5 \%$ and $24.5 \%$ reduction in the melting time for HTF inlet temperature of 80 ${ }^{\circ} \mathrm{C}$ and $85^{\circ} \mathrm{C}$, respectively, has been observed in comparison with the case without fins. Mat et al. [14] investigated the melting process of paraffin RT 82 in a finned triplex tube system with inside tube heating, outside tube heating, and both sides heating methods, as well as various fin configurations of the unit: internal, external and internal-external. Comparative analysis showed no significant difference among the three configurations in terms of PCM melting rate. It has been observed that as the melting process begins, heat is transferred to the PCM primarily by conduction and later by natural convection. This occurs because the solid region moves away from the heat transfer surface and the thickness of the liquid region grows along the heat transfer surface. The further 
melting is mostly governed by natural convection due to the density gradient within the liquid PCM and heat transfer by conduction almost becomes negligible as the melting process continues [15]. Akgun et al. [16] performed experimental investigation on melting of paraffin in a vertically oriented shell-and-tube unit. As a result of natural convection, as the PCM was heated from inner wall, the melted PCM extended radially outward and the molten region formed a conical shape. Regin et al. [17] analyzed the melting behavior of paraffin wax encapsulated in a cylindrical capsule surrounded by hot water. The experimental results showed the influence of natural convection on axisymmetric melting process; melting in top region was significantly faster than that in bottom.

As seen from the literature, insertion of fins is an effective way to counter the low thermal conductivity of most PCMs. Their careful design and implementation can significantly increase heat transfer and decrease total melting time. The purpose of this investigation was to experimentally observe the melting process in a shell-and-tube type LTES with longitudinal fins in order to expand existing knowledge on the subject. A series of measurements has been performed in order to evaluate the thermal response of this type of LTES during the charging process. Obtained results will serve as guidelines in modeling, design and optimization of shell-and-tube type LTES with longitudinal fins.

\section{EXPERIMENTAL SETUP}

\section{A. Test unit}

A vertically oriented shell-and-tube type tank (Fig. 1) has been designed and constructed, serving as the experimental test unit. It consists of an outer shell and 19 concentric tubes with longitudinal fins (Fig. 2). It is insulated with $25 \mathrm{~mm}$ of expanded rubber foam to minimize heat loss through the outer shell. The tank's outer shell, with the diameter of $0.95 \mathrm{~m}$ and total height of $1.5 \mathrm{~m}$, is made of stainless steel. Longitudinally finned tubes, with inner diameter of $0.025 \mathrm{~m}$ and outer diameter of $0.03 \mathrm{~m}$, are made of aluminum. Each tube contains a set of eight equidistant longitunidal fins, offset by an angle of $45^{\circ}$. Fins length is $0.066 \mathrm{~m}$ and their width is $0.002 \mathrm{~m}$.

Water, which serves as HTF, flows through the tubes, entering the unit at the top and exiting at the bottom. The shellside is filled with technical grade paraffin RT 25 . Its thermophysical properties are taken from the manufacturer's data sheet [18] and given in Table 1 .

A set of $30 \mathrm{~K}$-type thermocouples has been placed axially and radially throughout the paraffin-side of the tank, forming a $3 \times 3$ measuring field. They were placed at axial positions of $0.2 \mathrm{~m}, 0.75 \mathrm{~m}$ and $1.3 \mathrm{~m}$, with regard to the water inlet. At each axial level, three radial positions have been investigated, at radial distances of $0.035 \mathrm{~m}, 0.055 \mathrm{~m}$ and $0.075 \mathrm{~m}$, with respect to the tube center (Fig. 3). Two additional thermocouples have been placed at the HTF inlet and outlet positions to monitor the temperature variation at the HTF outlet. All thermocouples have been connected to the data acquisition system NI cDAQ-9174, containing the thermocouples module NI 9214. The acquisition system was linked with the personal computer and the software LabView was used to acquire and store measured data into a file. Temperature values were measured and stored at $10 \mathrm{~s}$ intervals. The measurement sensors had been calibrated prior

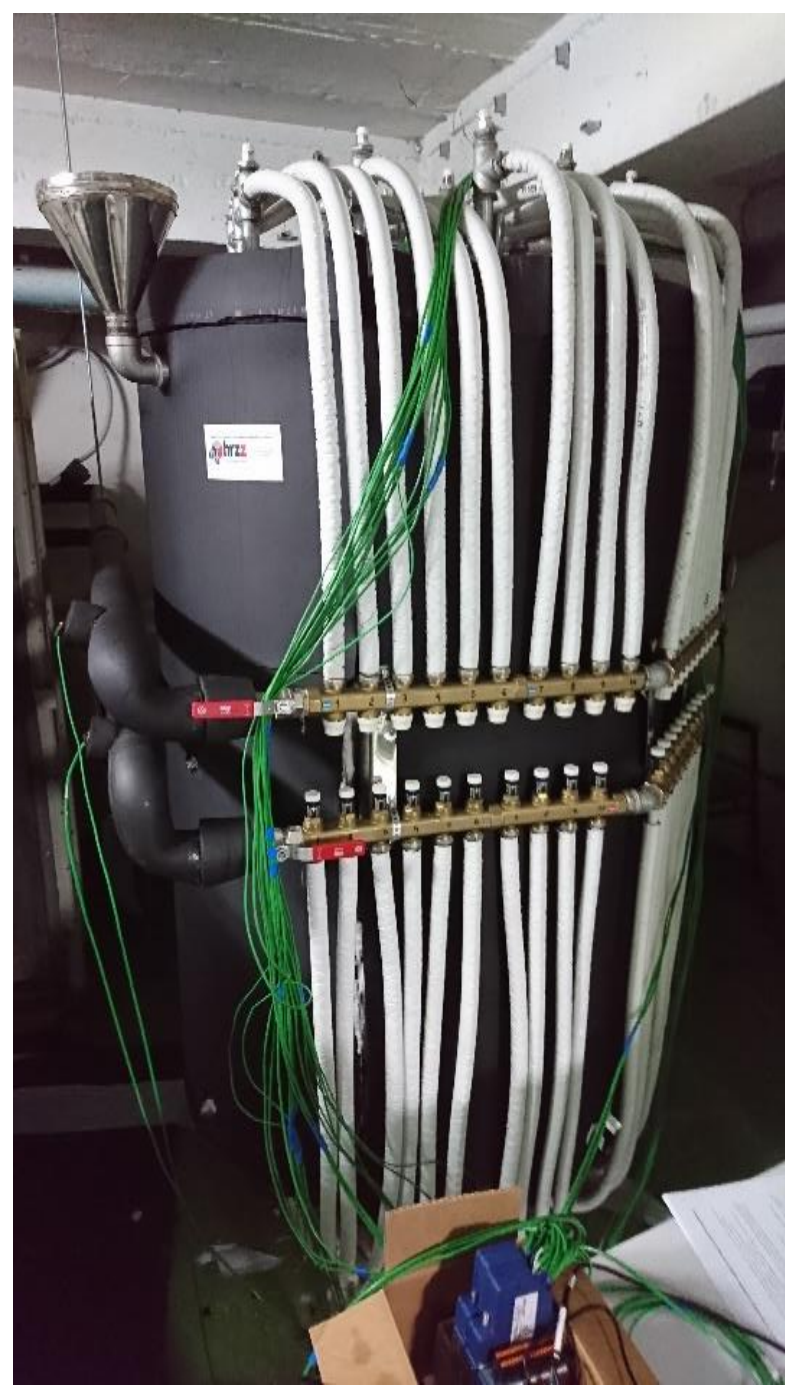

Fig 1. Latent thermal energy storage tank

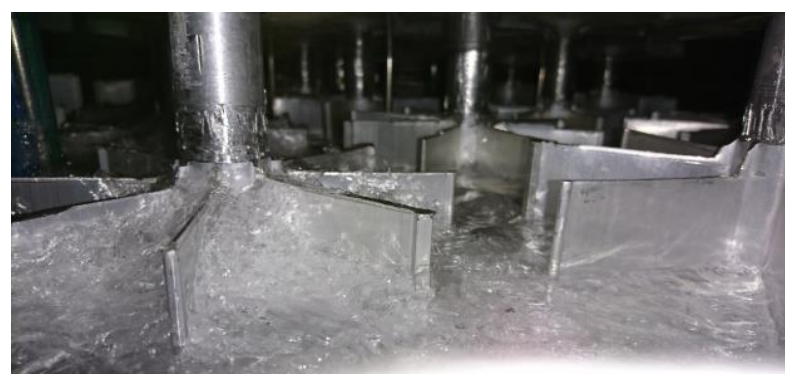

Fig 2. Tube configuration inside the LTES

Table 1. Thermophysical properties of paraffin RT 25

\begin{tabular}{|l|c|}
\hline Melting/solidification temperature range $\left[{ }^{\circ} \mathrm{C}\right]$ & $22-26$ \\
\hline Latent heat $[\mathrm{kJ} / \mathrm{kg}]$ & 170 \\
\hline Thermal conductivity $[\mathrm{W} / \mathrm{mK}]$ & 0.2 \\
\hline Specific heat $[\mathrm{J} / \mathrm{kgK}]$ & 2000 \\
\hline Density solid/liquid $\left[\mathrm{kg} / \mathrm{m}^{3}\right]$ & $880 / 760$ \\
\hline
\end{tabular}


to the experiement, using cold and hot water baths and a calibrated thermometer.

\section{B. Test system and experimental procedure}

A schematic diagram of the experimental system is presented on Fig. 4. Experimental rig consists of the previously described test unit, water-water heat pump, 3001 hot and cold water tanks, thermostatic three-way valve and circulation pumps in the condenser-hot tank circuit, evaporator-cold tank circut and working tank-test unit circuit. Water from the hot tank was used as HTF. The measurements have been performed at the Laboratory for thermal measurements at University of Rijeka, Faculty of Engineering.

Initial conditions for melting were defined by constant temperature of PCM, below melting point in all cases. Once the thermocouples on the paraffin-side of the tank all showed uniform temperature distribution, hot water at a set temperature from the hot tank entered the test unit. At that point, timewise acqusition and storing of temperature variations has been initiated.

Mass flow rate of HTF was constant and controlled by working tank-test unit pump. Constant HTF inlet temperature was maintained by the three-way thermostatic valve. Transient temperature variations of PCM during charging (melting) have been experimentally obtained. When all thermocouples had shown temperatures above the melting point, the experiment was finished.

\section{EXPERIMENTAL RESULTS AND DISCUSSION}

\section{A. Timewise temperature variations}

A set of experimental measurements has been performed in order to evaluate the influence of HTF inlet temperature on the thermal performance of LTES during charging process. $\mathrm{HTF}$ inlet temperatures varied from $37^{\circ} \mathrm{C}$ to $42^{\circ} \mathrm{C}$, while flow rate was $0,62 \mathrm{~m}^{3} / \mathrm{h}$ for all cases. Fig. 5 presents a comparison of obtained PCM temperature variations at position $r=0.055$ $\mathrm{m}$ and $\mathrm{x}=1.3 \mathrm{~m}$ for different values of HTF inlet temperature $\left(t_{\mathrm{w}, \text { in }}\right)$. It can be observed for all cases that initially, when paraffin was completely solid, heat transfer was governed by conduction alone and only sensible heat was exchanged, as evident by an increase in temperature during that stage. As the melting began, the liquid layer along the tube wall was formed and, natural convection added to the heat transfer, due to density gradient existing between the liquid PCM particles. As the liquid layer grew, natural convection became more dominant. It is worth noting that the effect of natural convection is the strongest at the top-most measured level of the LTES, since lighter PCM particles rise to the top of the tank, but also due to the fact that heat transfer between HTF and PCM is the strongest at that level, since HTF enters the LTES at the top. As temperature difference between HTF and PCM decreases, temperature increase in liquid PCM is less prominent in later stages of the process. It can be observed that melting is not isothermal, as it occurs in a temperature range between approximately $18{ }^{\circ} \mathrm{C}$ and $25{ }^{\circ} \mathrm{C}$ at measured positions. Similar phenomenon has been noted by Hasan [19] and Dimaano and Watanabe [20]. Also, similar behavior has been described in [21]. Once the paraffin has completely melted and all the latent heat has been released, a more intense

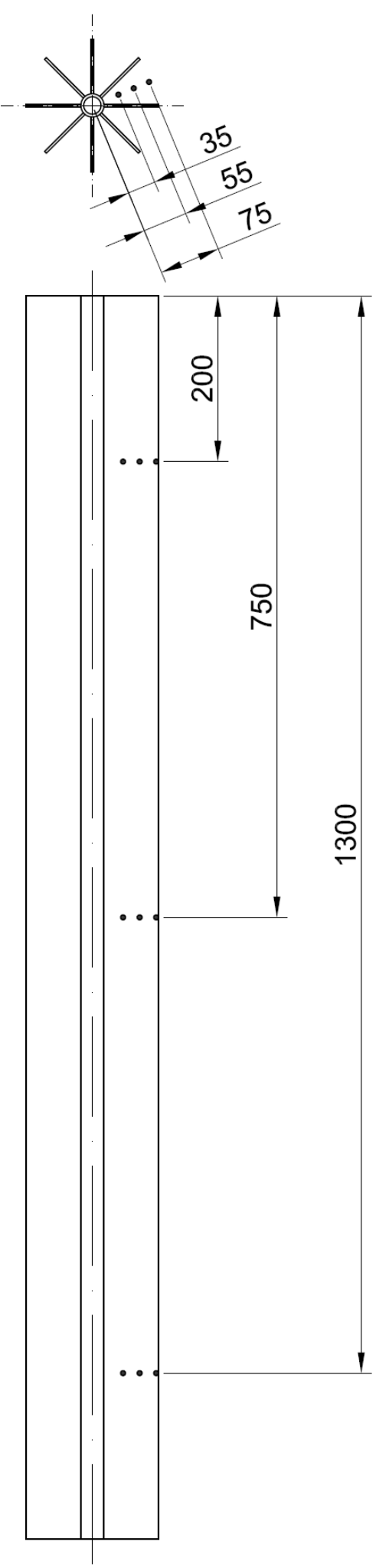

Fig 3. Schematic of tube geometry and position of thermocouples

increase in temperature is observed, i.e. sensible heat transfer in liquid PCM is governed by natural convection. The case with the highest HTF inlet temperature resulted in the shortest melting time and the one with the lowest HTF inlet temperature resulted in the longest melting time. From Fig. 5 it can also be noted that PCM is completely melted after reaching $25{ }^{\circ} \mathrm{C}$, as a more significant increase in temperature 
is observed later. It is evident that melting in the case of HTF inlet temperature $37^{\circ} \mathrm{C}$ is significantly slower than in cases with higher HTF inlet temperature, indicating the more intense natural convection-led heat transfer for the higher temperature cases.

Fig. 6 presents PCM temperature distributions at different radial positions for axial position $\mathrm{x}=0.75 \mathrm{~m}$ and for $\mathrm{HTF}$ inlet temperature $42{ }^{\circ} \mathrm{C}$. It can be observed that melting time is the shortest at the position $0.035 \mathrm{~m}$, the one closest to the tube, and is noticably shorter than at other two positions. As previously stated, natural convection evolves at the liquid layer formed near the tube, so its intensity is the strongest at the measurement position near the tube. Other radial positions are reached later, and consequently, their melting times are longer.

Comparing with Fig. 5, it can also be observed that melting time is significantly shorter at the $\mathrm{x}=0.75 \mathrm{~m}$ than at the $\mathrm{x}=$ $1.3 \mathrm{~m}$ for the same radial position and same HTF inlet temperature. Since natural convection is buoyancy-driven, lighter liquid PCM particles rise and enhance the heat transfer at higher measurement positions. Also, as mentioned, these positions are nearer to the water inlet, which also adds to the heat transfer. Melting times for all HTF inlet temperatures show similar trend; the higher the axial position, the faster the melting in all tested cases at equivalent radial positions.

\section{B. Stored thermal energy}

In order to evaluate heat storage capability of the presented LTES, total amount of stored thermal energy during the charging process has been calculated, compared and presented in Fig. 7 for various HTF inlet temperatures. The value of thermal energy has been obtained twofold; by calculating and comparing the released heat on the HTF-side of the tank in each measured timestep, and by calculating the absorbed thermal energy on the PCM-side in equivalent intervals based on PCM temperatures. The biggest discrepancy between this thermal balance is $8.4 \%$, and for this set of measurements, total amount of thermal energy ranges from $176 \mathrm{MJ}$ to $193 \mathrm{MJ}$, and it increases with HTF inlet temperature increase.

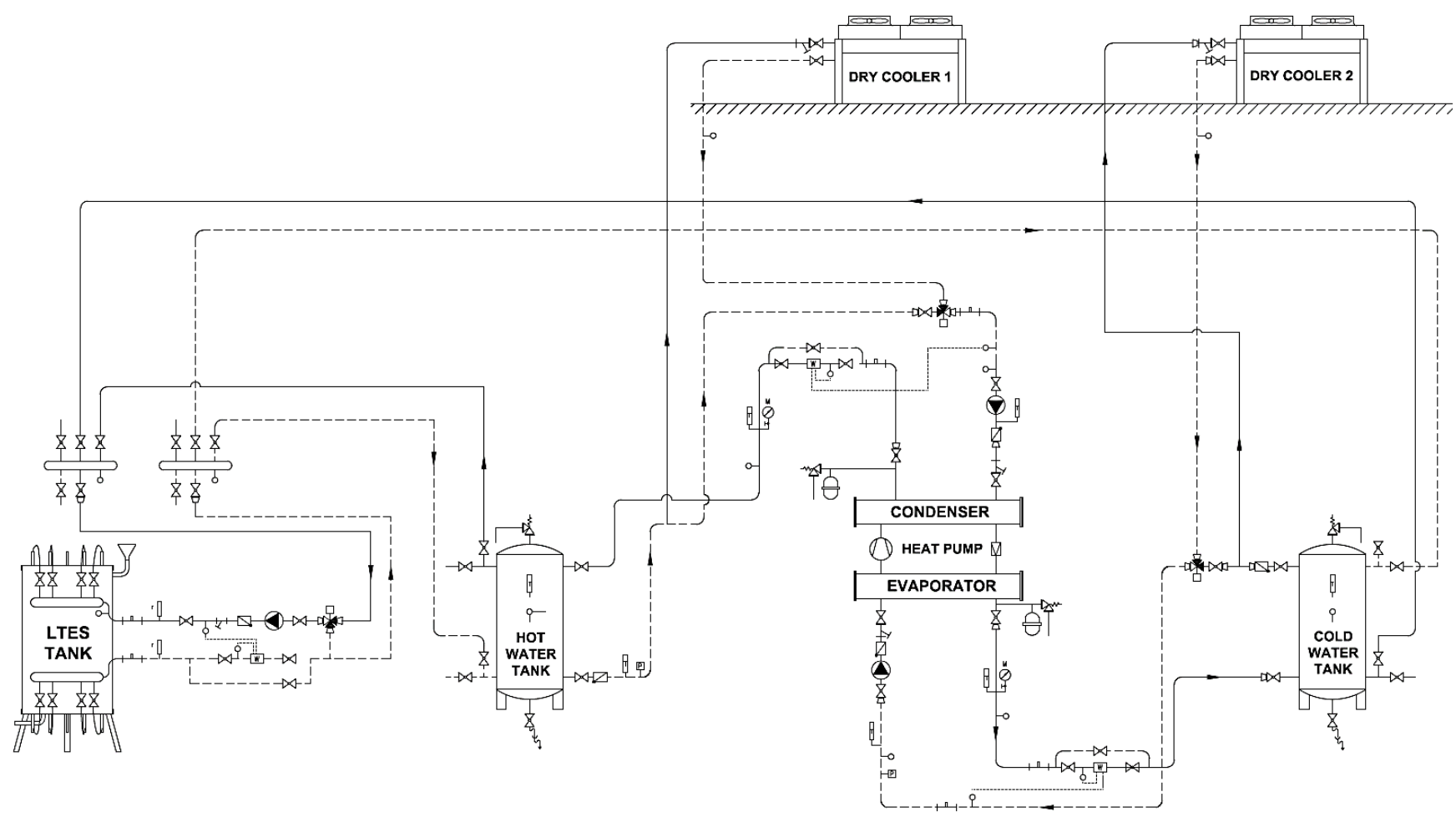

Fig 4. Schematic diagram of the experimental setup 


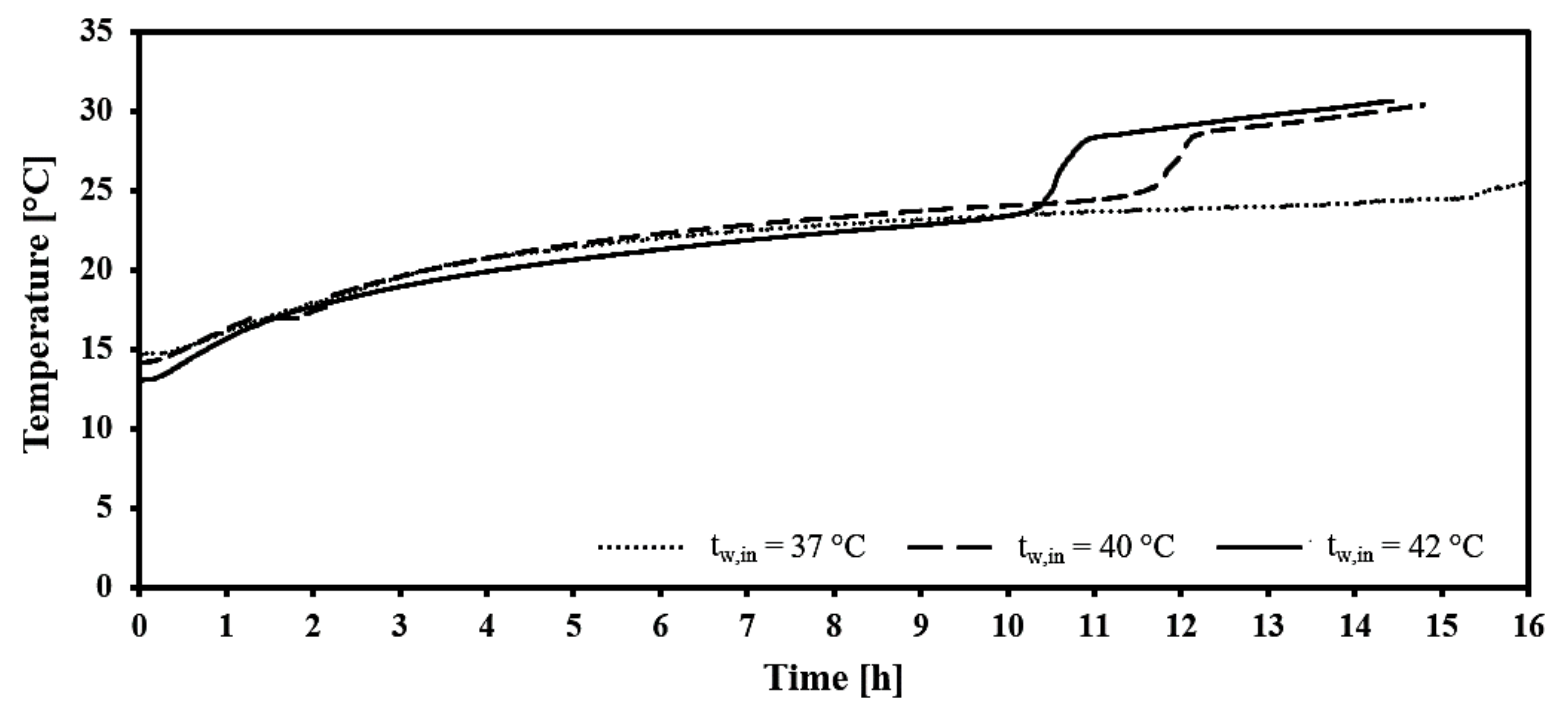

Fig. 5. Experimentally obtained timewise PCM temperature variations inside the latent thermal energy storage at position $r=0.055 \mathrm{~m}, x=1.3 \mathrm{~m}$ for different water inlet temperatures

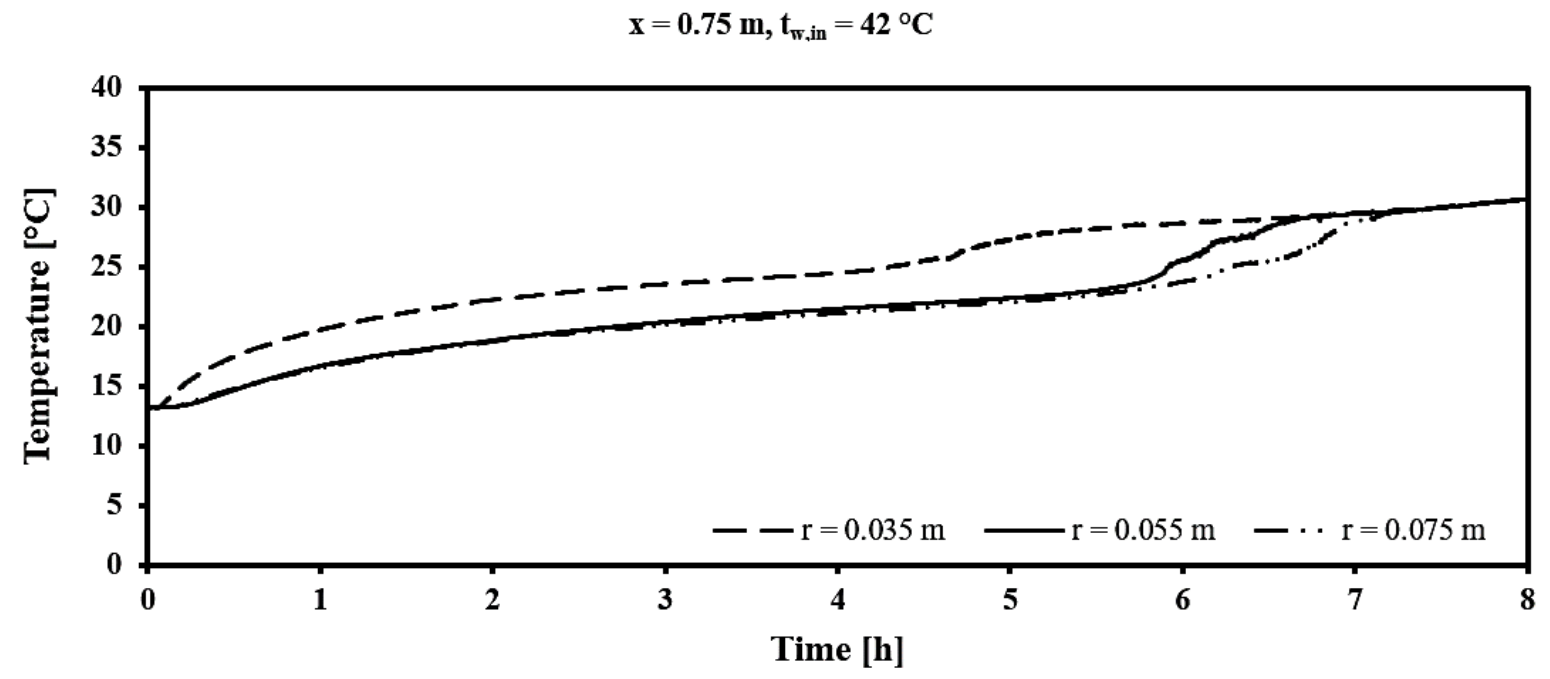

Fig 6. Experimentally obtained timewise PCM temperature variations inside the latent thermal energy storage for different radial positions at axial position $x=0.75 \mathrm{~m}$ and for water inlet temperature $42^{\circ} \mathrm{C}$

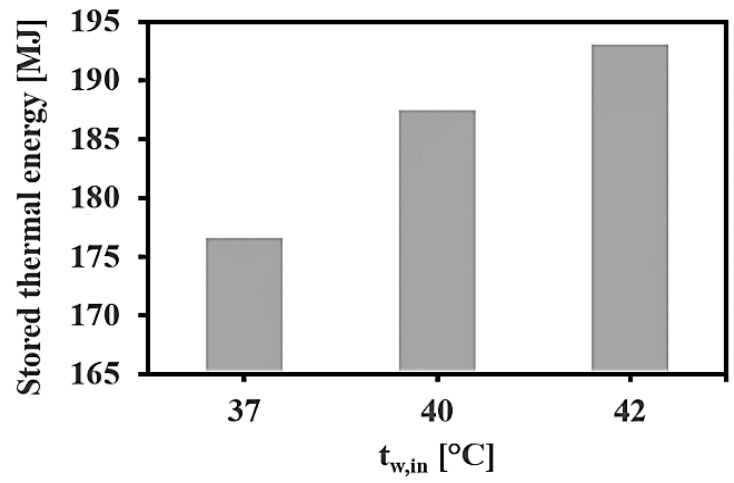

Fig 7. Stored thermal energy variations with respect to HTF inlet temperature

\section{CONCLUSION}

Melting process of paraffin RT 25 in a vertical shell-andtube type LTES with longitudinal fins has been experimentally investigated. A series of measurements has been performed for various HTF inlet temperatures in order to evaluate its influence on the melting. It has been determined that melting rate is the highest at the highest HTF inlet temperature. Influence of natural convection is observed with respect to values of HTF inlet temperature, as well as radial and axial distances. This buoyancy-driven motion caused by density gradient is the strongest at radial measurement points near the tube and at higher axial measurement points, near the HTF inlet. Values of total thermal energy stored have been calculated and reported for analyzed cases. Obtained experimental results expand the knowledge of paraffin 
melting in a LTES enhanced with longitudinal fins. They provide the basis for further research on modeling, design and optimization of this type of LTES.

\section{ACKNOWLEDGMENT}

This work has been supported in part by Croatian Science Foundation under the project HEXENER (IP-2016-06-4095) and in part by the University of Rijeka under the project number ,uniri-tehnic-18-69“.

\section{REFERENCES}

[1] G. Wei, G. Wang, C. Xu, X. Ju, L. Xing, X. Du, Y. Yang, "Selection principles and thermophysical properties of high temperature phase change materials for thermal energy storage: a review", Renewable and Sustainable Energy Reviews, 81(2), 2018, pp. 1771-1786.

[2] D. Zhao, G. Tan, "Numerical analysis of a shell-and-tube latent heat storage unit with fins for air-conditioning application", Applied Energy, 138, 2015, pp. 381-92.

[3] A.C. Marques, G.F. Davies, G.G. Maidment, J.A. Evans, I.D. Wood, "Novel design and performance enhancement of domestic refrigerators with thermal storage", Applied Thermal Engineering, 63, 2014, pp. 511-519.

[4] S. Thaker, A.O. Oni, E. Gemechu, A. Kumar, "Evaluating energy and greenhouse gas emission footprints of thermal energy storage systems for concentrated solar power applications", Journal of Energy Storage, 26, 2019, 100992

[5] N.I. Ibrahim, F.A. Al-Sulaiman, S. Rahman, B.S. Yilbas, A.Z. Sahin, "Heat transfer enhancement of phase change materials for thermal energy storage applications: A critical review", Renewable and Sustainable Energy Reviews, 74, 2017, pp. 26-50.

[6] M. Medrano, M.O. Yilmaz, M. Nogués, I. Martorell, J. Roca, L.F. Cabeza, "Experimental evaluation of commercial heat exchangers for use as PCM thermal storage systems", Applied Energy, 86(10), 2009, pp. 2047-2055.

[7] A.M. Abdulateef, S. Mat, J. Abdulateef, K. Sopian, A.A. Al-Abidi, "Geometric and design parameters of fins employed for enhancing thermal energy storage systems: a review", Renewable and Sustainable Energy Reviews, 82(1), 2018, pp. 1620-1635

[8] L. Kalapala, J.K. Devanuri, "Influence of operational and design parameters on the performance of a PCM based heat exchanger for thermal energy storage - A review", Journal of Energy Storage, 20, 2018, pp. 497-519.
[9] A.A. Al-Abidi, S. Mat, K. Sopian, M.Y. Sulaiman, C.H. Lim, T.H. Abdulrahman, "Review of thermal energy storage for air conditioning system”, Renewable and Sustainable Energy Reviews, 16(8), 2012, pp. 5802-5819.

[10] F. Agyenim, P. Eames, M. Smyth, "A comparison of heat transfer enhancement in a medium temperature thermal energy storage heat exchanger using fins", Solar Energy 83, 2009, pp. 1509-20.

[11] A. Gil, G. Peiró, E. Oró, L.F. Cabeza, "Experimental analysis of the effective thermal conductivity enhancement of PCM using finned tubes in high temperature bulk tanks", Applied Thermal Engineering, 142, 2018, pp. 736-744.

[12] A.A. Al-Abidi, S. Mat, K. Sopian, M.Y. Sulaiman, A.T. Mohammad, "Experimental study of melting and solidification of PCM in a triplex tube heat exchanger with fins", Energy and Buildings, 68, 2014, pp. 33-41.

[13] M.K. Rathod, J. Banerjee, "Thermal performance enhancement of shell and tube Latent Heat Storage Unit using longitudinal fins", Applied Thermal Engineering, 75, 2015, pp. 1084-1092.

[14] S. Mat, A.A. Al-Abidi, K. Sopian, M.Y. Sulaiman, A.T. Mohammad, "Enhance heat transfer for PCM melting in triplex tube with internalexternal fins", Energy Conversion and Management, 74, 2013, pp. 223-36

[15] S. Jegadheeswaran, S.D. Pohekar, "Performance enhancement in latent heat thermal storage system: a review", Renewable and Sustainable Energy Reviews, 13, 2009, pp. 2225-44.

[16] M. Akgun, O. Aydin, K. Kaygusuz, "Experimental study on melting/solidification characteristics of a paraffin as PCM", Energy Conversion and Management, 48, 2007, pp. 669-78.

[17] A.F. Regin, S.C. Solanki, J.S. Saini, "Latent heat thermal storage using cylindrical capsule: numerical and experimental investigations", Renewable Energy, 31, 2006, pp. 2025-41.

[18] Rubitherm GmbH, paraffin RT 25 data sheet, 2018.

[19] A. Hasan, "Phase change material energy storage system employing palmitic acid", Solar Energy 52, 1994, pp. 143-154.

[20] M.N.R. Dimaano, T. Watanabe, "Performance investigation of the capric and lauric acid mixture as latent heat energy storage for a cooling system", Solar Energy, 72, 2001, pp. 205-215.

[21] A. Trp, "An experimental and numerical investigation of heat transfer during technical grade paraffin melting and solidification in a shelland-tube latent thernal energy storage unit”, Solar Energy, 79, 2005, pp. 648-660. 